\title{
Clevidipine resistance in a patient taking aripiprazole and methylphenidate
}

\author{
This article was published in the following Dove Press journal: \\ Journal of Experimental Pharmacology \\ 17 October 2014 \\ Number of times this article has been viewed
}

\author{
M Alysse Jacklen' \\ Jason A Campagna ${ }^{2}$ \\ Joseph D Tobias ${ }^{3,4}$ \\ 'The Ohio State University College \\ of Medicine, Columbus, OH, USA; \\ ${ }^{2}$ Neuro and Critical Care, The \\ Medicines Company, Parsippany, NJ, \\ USA; ${ }^{3}$ Department of Anesthesiology \\ and Pain Medicine, The Ohio State \\ University, Columbus, OH, USA; \\ ${ }^{4}$ Department of Anesthesiology and \\ Pain Medicine, Nationwide Children's \\ Hospital, Columbus, OH, USA
}

\begin{abstract}
Various factors may be responsible for blood pressure alterations during perioperative care. When these physiologic alterations require treatment, several therapeutic options are available. Clevidipine is an ultrashort-acting, intravenous L-type calcium channel antagonist of the dihydropyridine class. Anecdotal experience has demonstrated its efficacy in various clinical scenarios in the pediatric population. We report apparent resistance to the vasodilatory effects of clevidipine in a 13-year-old girl who presented for anesthetic care during posterior spinal fusion for neuromuscular scoliosis whose chronic medication regimen included aripiprazole and methylphenidate for the treatment of depression and attention-deficit/hyperactivity disorder. We discuss the potential interaction of aripiprazole and methylphenidate with the calcium channel antagonists and cellular mechanisms responsible for the resistance to the vasodilatory effects of clevidipine.
\end{abstract}

Keywords: clevidipine, blood pressure, calcium channel antagonist, controlled hypotension, aripiprazole, posterior spinal fusion, labetalol

\section{Introduction}

Clevidipine (Cleviprex ${ }^{\circledR}$, The Medicines Company, Parsippany, NJ, USA) is an ultrashort-acting, intravenous calcium channel antagonist approved for the control of blood pressure (BP) in adult patients when oral therapy is neither feasible nor desirable. Like nicardipine, it is a member of the dihydropyridine class. Clevidipine undergoes rapid metabolism by nonspecific blood and tissue esterases, resulting in a context-insensitive half-life of approximately 1 minute. Clinical trials in adult surgical and nonsurgical populations have demonstrated its efficacy in rapidly controlling BP in various clinical scenarios with a favorable adverse effect profile. ${ }^{1-3}$ Anecdotal experience in the pediatric population has further demonstrated its efficacy in various clinical scenarios. ${ }^{4-6} \mathrm{We}$ report a 13-year-old girl with neuromuscular scoliosis who presented for anesthetic care during posterior spinal fusion with the plan to use clevidipine for controlled hypotension to limit intraoperative blood loss. Her chronic medication regimen included aripiprazole (Abilify $^{\circledR}$, Bristol-Myers Squibb, New York, NY, USA) and methylphenidate (Concerta ${ }^{\circledR}$, Janssen Pharmaceuticals, Titusville, NJ, USA) for the treatment of depression and attention-deficit/hyperactivity disorder (ADHD). Despite increasing the infusion rate to a maximum of $5 \mu \mathrm{g} / \mathrm{kg} / \mathrm{min}$, no response was noted. We discuss the potential interactions of aripiprazole and methylphenidate with the calcium channel antagonists and cellular mechanisms responsible for the resistance to the vasodilatory effects of clevidipine.

\section{Case report}

Institutional Review Board approval is not required for single case reports at Nationwide Children's Hospital (Columbus, OH, USA). The patient was a 13-year-old, 
$51.3 \mathrm{~kg}$ female who presented for posterior spinal fusion for correction of neuromuscular scoliosis. Her past medical history was significant for progressive scoliosis unresponsive to conservative treatment, including bracing. Additional comorbid conditions included ADHD and depression. Pertinent past surgical history included laminectomy with release of a tethered spinal cord at age 11 years. Current medications included methylphenidate (36 mg once a day) and aripiprazole (10 mg once a day). Preoperative laboratory data including complete blood count, platelet count, and coagulation function were within normal limits. The patient was held nil per os for solids for 8 hours and clear liquids for 2 hours. In the perioperative surgical unit her BP was $123 / 69 \mathrm{mmHg}$, heart rate was 120 beats/minute, oxygen saturation was $99 \%$ while breathing room air, and body temperature was $36.6^{\circ} \mathrm{C}$. The patient was brought to the operating room and standard American Society of Anesthesiologists monitors were placed. Anesthesia was induced via inhalation of sevoflurane in oxygen/nitrous oxide, and peripheral intravenous access was achieved. Fentanyl $(100 \mu \mathrm{g})$ and propofol ( $1 \mathrm{mg} / \mathrm{kg}$ ) were then administered and neuromuscular blockade was provided by rocuronium $(0.6 \mathrm{mg} / \mathrm{kg})$. Direct laryngoscopy was performed and a $6.0 \mathrm{~mm}$ cuffed endotracheal tube was placed. After anesthetic induction, a second large bore peripheral intravenous cannula and a radial arterial catheter were placed. Maintenance anesthesia consisted of desflurane in air/oxygen titrated to maintain the bispectral index at 40-60 and a remifentanil infusion adjusted from $0.05 \mu \mathrm{g} / \mathrm{kg} / \mathrm{min}$ up to $0.3 \mu \mathrm{g} / \mathrm{kg} / \mathrm{min}$ to maintain the mean arterial pressure (MAP) at $55-65 \mathrm{mmHg}$. The patient was positioned prone on a Jackson table. Normothermia was maintained using forced air warming. Per our usual routine, controlled hypotension using clevidipine was planned as part of the anesthetic technique to limit blood loss and the need for allogeneic blood products. The clevidipine infusion is initiated if the MAP cannot be maintained at $<65 \mathrm{mmHg}$ despite a remifentanil infusion of $0.3 \mu \mathrm{g} / \mathrm{kg} / \mathrm{min}$. Additional techniques to limit intraoperative blood loss and the need for allogeneic transfusions included the administration of tranexamic acid and intraoperative cell salvage. Motor and somatosensory evoked potentials were monitored intraoperatively throughout the surgery. During the procedure, despite a remifentanil infusion at $0.3 \mu \mathrm{g} / \mathrm{kg} / \mathrm{min}$, the MAP was $\geq 65 \mathrm{mmHg}$ and clevidipine was added in an attempt to further decrease the MAP to $55-65 \mathrm{mmHg}$. The infusion was started at $1 \mu \mathrm{g} / \mathrm{kg} / \mathrm{min}$ and increased every 2 minutes by $1 \mu \mathrm{g} / \mathrm{kg} / \mathrm{min}$. Despite the maximum suggested labeled clevidipine infusion of $5 \mu \mathrm{g} / \mathrm{kg} / \mathrm{min}$, the MAP remained at
70-75 mmHg. While continuing the clevidipine infusion, labetalol (incremental doses of $0.1 \mathrm{mg} / \mathrm{kg}$ ) were required to achieve the target MAP of 55-65 $\mathrm{mmHg}$. Following the second dose of labetalol (total of $0.2 \mathrm{mg} / \mathrm{kg}$ ), the MAP decreased from $75-80 \mathrm{mmHg}$ to $60-65 \mathrm{mmHg}$. Three more doses of labetalol $(0.1 \mathrm{mg} / \mathrm{kg})$ were administered over the next 75 minutes to maintain the MAP at $55-65 \mathrm{mmHg}$. Following completion of the surgical procedure, the patient's trachea was extubated and she was transferred to the postanesthesia care unit in a stable condition. Postoperative analgesia was provided by hydromorphone administered by a patient-controlled analgesia device. She was admitted to the inpatient ward. The remainder of her postoperative course was unremarkable and she was discharged home on postoperative day 4.

\section{Discussion}

The administration of allogeneic blood products has been shown to have a negative impact on postoperative outcome following major surgical procedures. ${ }^{7}$ Given these concerns, several techniques are generally employed to limit intraoperative blood loss and therefore the need for allogeneic blood products. These techniques include appropriate positioning on the Jackson table to limit pressure on the abdomen and the engorgement of epidural veins, maintenance of normothermia, controlled hypotension, the administration of antifibrinolytic agents, and intraoperative cell salvage. ${ }^{7}$ Controlled hypotension, a technique commonly employed during major orthopedic surgery, involves the deliberate lowering of the MAP to 55-65 mmHg. Although several pharmacologic agents may be used for this purpose, our current clinical preference is the ultrashort-acting calcium channel antagonist clevidipine. ${ }^{8,9}$ In a previous retrospective report, clevidipine was shown to effectively provide controlled hypotension during spinal fusion in a cohort of 20 adolescents ranging in age from 14 years to 18 years and in weight from $46 \mathrm{~kg}$ to $96 \mathrm{~kg}$. ${ }^{6}$ To maintain the MAP at $55-65 \mathrm{mmHg}$, the maintenance infusion rate of clevidipine varied from $1 \mu \mathrm{g} / \mathrm{kg} / \mathrm{min}$ to $5 \mu \mathrm{g} / \mathrm{kg} / \mathrm{min}$, with an average infusion rate of $2.9 \pm 0.7 \mu \mathrm{g} / \mathrm{kg} / \mathrm{min}$. According to the clevidipine package insert, this dose is in the middle of the linear dose response range for the drug in adult patients. In this retrospective review and a more recent prospective trial, the patient in this report represents the only failure in a pediatric population. ${ }^{6,9}$ The patient whom we report was enrolled in an open-label, observational study focusing on the use of clevidipine for controlled hypotension during posterior spinal fusion for neuromuscular scoliosis. The outcome of that trial has been 
published previously, including mention of this patient who represented the only failure of clevidipine in that cohort of 50 patients. ${ }^{9}$ As noted in the current case report, there was no change in our patient's MAP despite a clevidipine infusion that had been increased up to $5 \mu \mathrm{g} / \mathrm{kg} / \mathrm{min}$. The MAP remained at $70-75 \mathrm{mmHg}$. Control of the MAP was eventually achieved with the intermittent administration of labetalol during the remainder of the procedure. This being the only case to date representing a clinical failure of clevidipine in our clinical experience of approximately 200 patients over a 10 -year period, it led us to consider possible drug-drug interactions with the patient's current medications, including aripiprazole and methylphenidate.

Clevidipine is an intravenous ultrashort-acting, L-type calcium channel antagonist that directly and selectively acts on peripheral vascular smooth muscle to dilate resistance arterioles. As a third-generation dihydropyridine calcium channel antagonist, it acts to rapidly decrease and stabilize BP. Although it has no direct effects on cardiac function, its vasodilatory properties may lead to reflex tachycardia and, potentially, stimulation of the sympathetic nervous system. These effects, although present, have been shown to be less with the dihydropyridine calcium channel antagonists (nicardipine and clevidipine) than with other direct-acting vasodilators such as sodium nitroprusside. ${ }^{1-3}$ However, our clinical experience has suggested that reflex tachycardia may be more common with clevidipine than with nicardipine. ${ }^{4-6,9-11}$

L-type calcium channel antagonists work at the terminal effect site for the sympathetic nervous system. Elevated sympathetic outflow eventually results in the release of norepinephrine, which binds to $\alpha$-adrenergic receptors on vascular smooth muscle, resulting in membrane depolarization and opening of voltage gated L-type calcium channels. These channels allow calcium to enter the muscle cell, eventually resulting in vascular smooth muscle contraction. The dose response curves for clevidipine (and other L-type dihydropyridine calcium channel antagonists) depend on the level of sympathetic tone. ${ }^{12}$ In adults with severe intracranial hemorrhage or subarachnoid bleeding, significant rightward shifts in the dose response relationship for clevidipine have been noted (The Medicines Company, data on file). These patients are experiencing a powerful neutrally mediated vasopressor response and have elevated levels of plasma catecholamines. ${ }^{13}$ We postulate that chronic stimulation of the sympathetic nervous system in a patient taking medications such as aripiprazole and methylphenidate may be one plausible mechanism for the resistance to clevidipine that we observed in our patient.
Aripiprazole is an atypical quinolinone antipsychotic with approved use in the treatment of major depressive and psychotic disorders. It is a partial agonist at dopamine receptors $\left(\mathrm{D}_{2} / \mathrm{D}_{3}\right)$ and a partial agonist at serotonin receptors (5-HT1A), thereby making it an aminergic agonist. ${ }^{14}$ Furthermore, aripiprazole has moderate affinity at other sites, including dopamine $\left(\mathrm{D}_{4}\right)$, serotonin (5-HT2C, 5-HT7), $\alpha_{1}$-adrenergic, and $\mathrm{H}_{1}$ receptors. Previous anecdotal reports have documented the occurrence of hypertension during therapy with aripiprazole and resolution following its discontinuation. ${ }^{15-18}$ While none of these reports has conclusively demonstrated the mechanism for this hypertension, Borras and Constant ${ }^{18}$ noted successful treatment with propranolol, suggesting that the sympathetic nervous system with adrenergic hyperactivity was the primary mechanism for the alterations in BP.

Our patient was also receiving methylphenidate as part of her chronic medication regimen. Alterations in BP have also been noted with methylphenidate, with the primary mechanism postulated to be the result of increased central and peripheral concentrations of dopamine, norepinephrine, and epinephrine. ${ }^{19}$ We would postulate that the combined effects of these two medications (aripiprazole and methylphenidate) may augment the normal surgical stress response that is mediated by the sympathetic nervous system. This sympathetic release of endogenous catecholamines, including norepinephrine and epinephrine, modulates perioperative alterations in $\mathrm{BP}$, an effect appreciated even in patients without a prior history of hypertension. ${ }^{20}$ While an exact mechanism cannot be determined for the resistance to clevidipine noted in our patient, we would postulate that the combination of medications either increased the normal sympathetic response to surgery or potentiated the response at the level of the vascular smooth muscle. The involvement of the sympathetic nervous system is further supported by our patient's response to labetalol, a mixed $\alpha$ - and $\beta$-adrenergic antagonist.

In summary, we present anecdotal evidence for resistance to the direct vasodilatory effects of clevidipine in a patient chronically receiving methylphenidate and aripiprazole. We would postulate that the mechanism involves the sympathetic nervous system with either increased release of endogenous catecholamines or an augmented effect of these agents on the smooth muscle of the vasculature. In such clinical scenarios, medications that act primarily through blocking the sympathetic nervous system or its peripheral effects, such as with labetalol, appear to be a logical choice for BP control.

\section{Disclosure}

The authors report no conflicts of interest in this work. 


\section{References}

1. Levy JH, Mancao MY, Gitter R, et al. Clevidipine effectively and rapidly controls blood pressure preoperatively in cardiac surgery patients: the results of the randomized, placebo-controlled efficacy study of clevidipine assessing its preoperative antihypertensive effect in cardiac surgery. Anesth Analg. 2007;105:918-925.

2. Singla N, Warltier DC, Gandhi SD, et al. Treatment of acute postoperative hypertension in cardiac surgery patients: an efficacy study of clevidipine assessing its postoperative antihypertensive effect in cardiac surgery-2 (ESCAPE-2), a randomized, double-blind, placebo-controlled trial. Anesth Analg. 2008;107:59-67.

3. Aronson S, Dyke CM, Stierer KA, et al. The ECLIPSE trials: comparative studies of clevidipine to nitroglycerin, sodium nitroprusside, and nicardipine for acute hypertension treatment in cardiac surgery patients. Anesth Analg. 2008;107:1110-1121.

4. Towe E, Tobias JD. Preliminary experience with clevidipine in the pediatric population. J Intensive Care Med. 2010;25:349-352.

5. Tobias JD, Schechter WS, Phillips A, et al. Clevidipine for perioperative blood pressure control in infants and children undergoing cardiac surgery for congenital heart disease. J Pediatr Pharmacol Ther. 2011;16: 55-60.

6. Tobias JD, Hoernschemeyer DG. Clevidipine for controlled hypotension during spinal surgery in adolescents. J Neurosurg Anesthesiol. 2011;23:347-351.

7. Tobias JD. Strategies for minimizing blood loss in orthopedic surgery. Semin Hematol. 2004;41:145-156.

8. Tobias JD. Controlled hypotension in children: a critical review of available agents. Paediatr Drugs. 2002;4:439-453.

9. Kako H, Gable A, Martin D, et al. A prospective, open-label trial of clevidipine for controlled hypotension during posterior spinal fusion in adolescents. J Pediatr Pharm Therap. In press.
10. Tobias JD, Hersey S, Mencio GA, Green NE. Nicardipine for controlled hypotension during spinal surgery. J Pediatr Orthop. 1996; $16: 370-373$

11. Tobias JD. Nicardipine to control mean arterial pressure after cardiothoracic surgery in infants and children. Am J Ther. 2001;8:3-6.

12. Pedrinelli R, Tarazi RC. Interference of calcium entry blockade in vivo with pressor responses to alpha-adrenergic stimulation: effects of two unrelated blockers on responses to both exogenous and endogenously released norepinephrine. Circulation. 1984;69:1171-1176.

13. Myers MG, Norris JW, Hachniski VC, Sole MJ. Plasma norepinephrine in stroke. Stroke. 1981;12:200-204.

14. Chen TY, Tzeng NS. Aripiprazole: a dopamine modulator that mimics methylphenidate in producing faster antidepressant effects. Med Hypotheses. 2013;81:183-185.

15. Hsiao YL, Chen SJ, Shen TW, Chang CH, Chen ST. Aripiprazole augmentation induced hypertension in major depressive disorder: a case report. Prog Neuropsychopharmacol Biol Psychiatry. 2011;35: 305-306.

16. Bat-Pitault F, Delorme R. Aripiprazole and hypertension in adolescents. J Child Adolesc Psychopharmacol. 2009;19:601-602.

17. Yasui-Furukori N, Fujii A. Worsened hypertension control induced by aripiprazole. Neuropsychiatr Dis Treat. 2013;9:505-507.

18. Borras L, Constant EL. Hypertension and aripiprazole. Am J Psych. 2005;162:12.

19. Volkow ND, Wang GJ, Fowler JS, et al. Cardiovascular effects of methylphenidate in humans are associated with increases of dopamine in brain and of epinephrine in plasma. Psychopharmacology. 2003;166:264-270.

20. Nordlander M, Pfaffendorf M, van Wezel HB. Calcium channel antagonists for perioperative blood pressure control. Semin Cardiothor Vasc Anesth. 1998;2:231-242.
Journal of Experimental Pharmacology

\section{Publish your work in this journal}

The Journal of Experimental Pharmacology is an international, peerreviewed, open access journal publishing original research, reports, reviews and commentaries on all areas of laboratory and experimental pharmacology. The manuscript management system is completely online and includes a very quick and fair peer-review system.

\section{Dovepress}

Visit http://www.dovepress.com/testimonials.php to read real quotes from published authors. 